\title{
Analysis of crack formation in germanium substrate at AllnGaP die bonding process
}

\author{
Luruthudass Annaniah*, Mutharasu Devarajan \\ School of Physics, University Sains Malaysia, Penang, Malaysia \\ Email address: \\ luruthudass@osram-os.com (L. Annaniah), mutharasu@usm.my (M. Devarajan)
}

\section{To cite this article:}

Luruthudass Annaniah, Mutharasu Devarajan. Analysis of Crack Formation in Germanium Substrate at AlInGaP Die Bonding Process. International Journal of Materials Science and Applications. Vol. 4, No. 1, 2015, pp. 1-6. doi: 10.11648/j.ijmsa.20150401.11

\begin{abstract}
Cracked die is a serious failure mode in Light Emitting Diode (LED) industry - affecting the LED quality and long-term reliability performance. In this paper, an investigation has been carried out to find out a relation between die bonding force and the occurrence of die crack at Germanium (Ge) substrate due to die attach (DA) ejector pin indentation. Based on the analysis, the results show that cracks start to occur at 60 gram-force (gF) bond force and above. The crack length at the die substrate increases with respect to the bond force. These indented dies were further analyzed by using Scanning Electron Microscope (SEM). The results show plastic deformation, slip traces and material pile-up at the vicinity of ejector pin crater. Some samples were sectioned using Focus Ion Beam (FIB) and it was found the crack depth does not exceed beyond $20.5 \mu \mathrm{m}$ and it follows the (111) plane. These findings, concludes that cracks start to appear at $60 \mathrm{gF}$ and they are confined to surface level even indented at extreme load $(140 \mathrm{gF})$. These cracks are far away from the active region of LED.
\end{abstract}

Keywords: Crack Die, LED Reliability, Bond Force Indentation, Ge (Germanium), Ejector Pin, Stress, Surface Deformation, Slip-Trace

\section{Introduction}

The reliability of Light Emitting Diode (LED) devices is a major concern in the illumination industry $[1,2]$. Thermo-mechanical stress failure in LED is one of the causes of LED components reliability issues and for a certain extent of LED failures [3 - 5].

When LED undergoes periodical on-off switching or environmental temperatures variations, the LED components experience thermo-mechanical stresses in cycles which are due to a mis-match of the Coefficient of Thermal Expansion (CTE) of the constituent materials [6 - 8]. If the die contain pre-damaged (crack) during LED manufacturing process, it would easily fail when it undergoes this stress and strain. Semiconductor manufacturing processes do create such issues to the die quality [9]. The work by Chen et.al stated that large deep scratches created by wafer thinning process significantly affected the strength of Si die [10].

There are many types of die cracks; most of them are easily detected like crack at the surface of the die. However, a crack at the bottom of the die (substrate) is difficult to detect because this crack is hidden, whereas back of the die will be attached with glue to a substrate. If the crack did not reach the epitaxial layer as shown in figure 1-a and 1-b, then it will not show any electrical abnormalities during outgoing electro-optical testing. However, it may fail during operation.

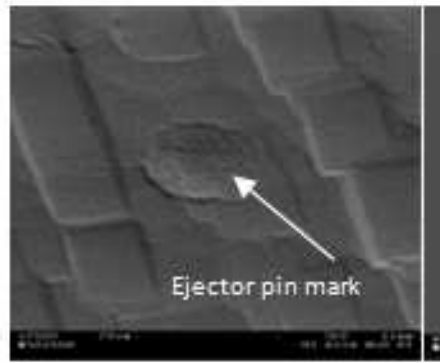

(a)

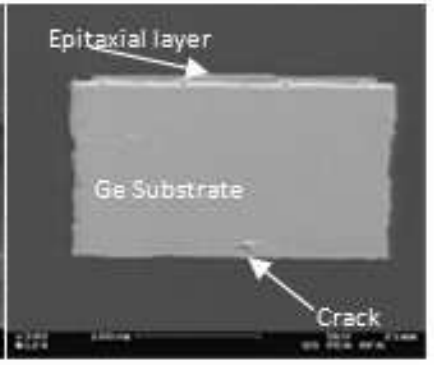

(b)
Figure 1. a. Substrate with ejector pin indentation mark b. Cross section view of the die with crack at indented substrate and die epitaxial layer.

Crack at substrate is mainly due to the die attach (DA) process. To avoid such cracks in the LED industry, the process engineer usually reduces the bond load by reducing the ejector speed and ejector pin height [11]. However, by slowing the ejector speed, the productivity is dropped. On the other hand, when reducing the ejector pin height, the die will not be 
pushed out of mylar correctly and the die will be tilted [11]. As a result, the die will be wrongly placed in the LED package. This is not desired in the LED industry.

In view of this situation, an investigation has been carried out to understand a relationship between the bond force and the die crack at Germanium (Ge) substrate of AlInGaP die. This Ge substrate used in the AlInGaP die, is a single crystal $\mathrm{Ge}$, having face-centre-cubic (FCC) diamond-type lattice with (111) plane [12, 13]. It is brittle at room temperature and it has been commonly used as a substrate in the Opto semiconductor industry for long time due to several advantages over Gallium Arsenide (GaAs).

\section{Theoretical Background}

\subsection{Nanoindentation Studies on Germanium}

Much research has been carried out to understand the Ge mechanical properties through nanoindentation techniques. Bradby et. al.[14] found that using the spherical indenter of $\sim 4.2 \mu \mathrm{m}$ at maximum load of $50 \mathrm{mN}, \mathrm{Ge}$ gives plastic deformation and dislocation at near the specimen surface $(0.6 \mu \mathrm{m}$ to $1.3 \mu \mathrm{m})$, however, no cracking observed [14]. Learning from this, the load used was $40 \mathrm{gF}(0.39 \mathrm{~N})$ to $140 \mathrm{gF}$ $(1.37 \mathrm{~N})$ for this experiment to anticipate crack at the $\mathrm{Ge}$ substrate. Theoretically for a crack to occur, the atomic bonds across a lattice plane must be broken and this requires a certain amount of load (force) $[15,16]$.

\subsection{Die Attach Process and Ejector Pin Stress on Ge Substrate}

In the LED packaging industry, most of the DA processes follow a similar die bonding sequence as illustrated in figure 2 (a-e). The most critical bonding sequence where cracks may occur is shown in figure 2-c. Here the ejector pin gives maximum impact stress at the bottom of die while the bond head holds the die at its other end.

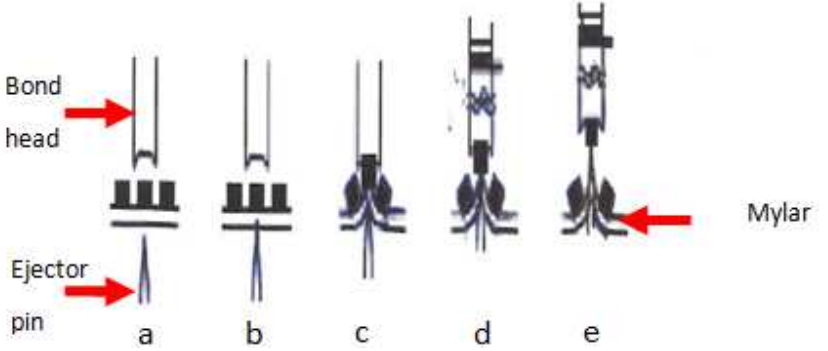

Figure 2. Illustrates the DA process where the ejector pin push and indent the die [11].

The stress applied on the die can be described by the Hertzian contact equation [17]. Normal stress applied on the die substrate can be expressed as:

$$
\sigma=\mathrm{F} / \mathrm{A}
$$

Where:

$\mathrm{A}$ is the area of ejector pin in contact.
F is the load (force) which the ejector pin applies on the die.

The ejector pin tip, which is semi-spherical in shape, is illustrated in figure 3 . It is the standard ejector pin supplied for the LED industry by Micro-mechanics [18]. The ejector pin tip radius, $\mathrm{R}$, for this research is $25 \mu \mathrm{m}$. This radius was used because it is commonly used for the small die size $(300 \mu \mathrm{m} \mathrm{X}$ $300 \mu \mathrm{m})$. The ejector pin contact area can be derived as

$$
\mathrm{A}=\pi \mathrm{a}^{2}
$$

Where, $a$, is the ejector pin spherical surface contact length as illustrated in figure 4 . Note that the Hertzian contact analysis is restricted to condition that the depth of penetration is small relative to the radius, $\mathrm{R}$, of the sphere [19]. In the present work the ejector pin contact " $\mathrm{a}$ " is measured $(\sim 5 \mu \mathrm{m})$ which is quite small as compared to R.

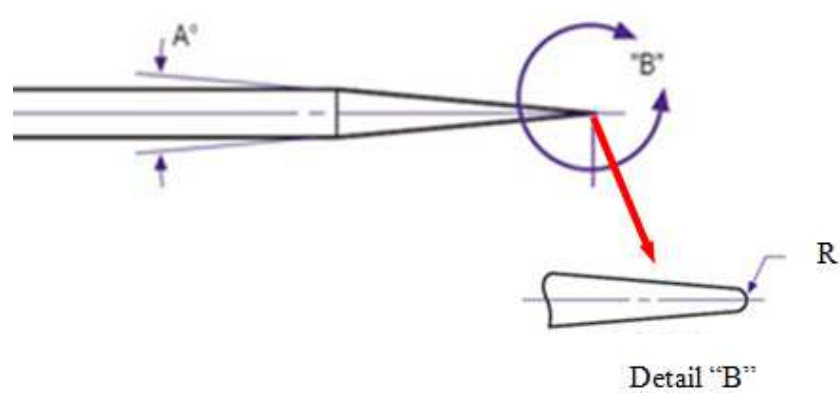

Figure 3. Schematic diagram of ejector pin and its semi spherical tip [18].

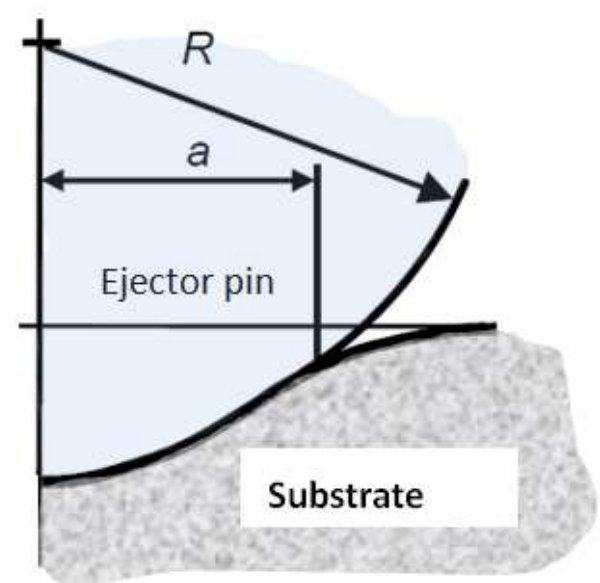

Figure 4. The ejector pin contact to substrate [17].

Combining equation 2 to equation 1 , the stress can be addressed as follows:

$$
\sigma=F / \pi a^{2}
$$

The stress applied to the die is directly proportional to the force applied; hence, the higher the force applied to the die, the higher the stress absorbed by the die. On the other hand the stress is inversely proportional to ejector pin tip contact area [17].

The bond force calculated using Newton's second law;

$$
\mathrm{F}=\text { mà }
$$


Where $m$ is the mass and $\dot{a}$ is the acceleration of the ejector pin.

$$
\dot{\mathrm{a}}=\left(\mathrm{v}_{2}-\mathrm{v}_{1}\right) / \mathrm{t}
$$

$v_{2}$ is the velocity of the ejector pin before hitting the back of the die (ejector pin speed). $\quad v_{l}$ is the velocity of ejector pin at datum. $t$ is the time taken for the ejector pin to move from datum to the point of impact on die. The maximum bond force, $\mathrm{F}$, can be addressed by combining equation 5 to equation 4 and by considering $v_{l}=0$ at the datum.

$$
F=m \cdot v_{2} / t
$$

Henceforth, the maximum stress applied on the die can also be addressed as:

$$
F=m \cdot v_{2} / \pi a^{2} . t
$$

The velocity the ejector pin travels before hitting the die is directly proportional to the stress applied on the die. Hence, the higher the ejector pin velocity, the higher the stress is at the chip substrate and these increases the possibilities to have crack die [11].

In the LED packaging industry DA process, the optimum bond force varies. It is influenced by the equipment, die size and the type of mylar carrier tape on which the dies were mounted

\section{Experimental Methodology}

\subsection{Sample Preparation}

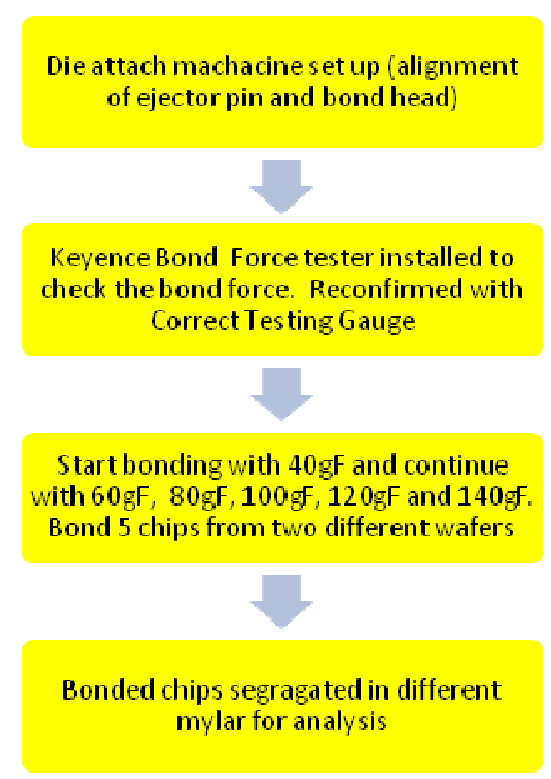

Figure 5. Sample preparation flow chart.

The sample preparation is described in the process flow shown in figure 5. Tested good AlInGaP dies with Ge substrate were selected for this evaluation and they were serialized on a mylar carrier tape for traceability purpose. DA equipment was set up and the ejector pin and bond head were checked for alignment and bonding stability. A Keyence bond force tester was installed on the bonder to check the bond force. Several bonding trials were carried out to check the bonding consistency. Final confirmation of the bonding consistency was carried out by using a hand held bond force tester - Correx Tension Gauge [20]. This is to counter confirm the Keyence bond force tester measurement accuracy before commencing the experiment.

The experiment conducted at room temperature, commenced with indentation force of $40 \mathrm{gF}$ and continued with $60 \mathrm{gf}, 80 \mathrm{gf}, 100 \mathrm{gf}, 120 \mathrm{gf}$ and $140 \mathrm{gf}$ respectively. Each cell consists of 5 dies. Bonded dies were segregated by using different Mylar to avoid mixing.

\subsection{Characterization Technique}

Crack length was measured with optical microscope (Leica-DMRE) at magnification 1000X and the average crack length was calculated. The indented dies were Ion Milled (IM) at $5.1 \mathrm{KeV}$ at a current of $180 \mu \mathrm{A}$ for 15 minutes to remove the thin Platinum (Pt) and Gold $(\mathrm{Au})$ metallization layer. Once the IM process was completed, the dies were analysed using the SEM (Hitachi - SU8020). Some of the dies were further sectioned using Focus Ion Beam (FIB) and analysed using SEM.

\section{Result and Discussion}

\subsection{Result}

Figure 6 shows the variations in the fracture length with the bond force. The crack length increases with increase of bond force. The increase was quite sharp from $60 \mathrm{gF}$ to $80 \mathrm{gF}$, however after $80 \mathrm{gF}$ one crack length gradually increases linearly.

As seen from the figure, there is no much appreciable difference between the batch 1 and 2 . This indicates that the mechanical properties remain constant.

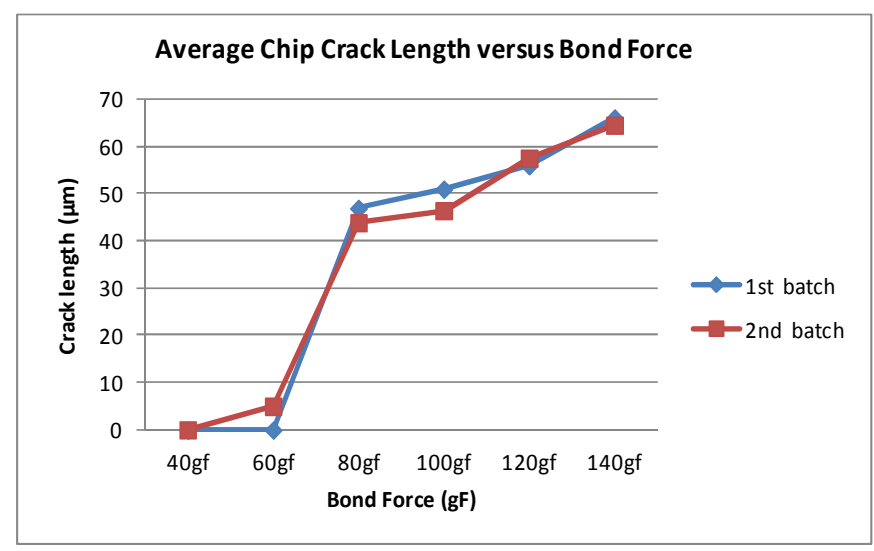

Figure 6. Average Crack Length versus Bond Force.

The optical micrographs representing the backside of the die surfaces are displayed in figures 7 (a-f). From the figures, it can readily be observed that the deformation on the die backside increases with increase of the bond force whereas the cracks can be seen in the specimens at $80 \mathrm{gF}$ and above. 


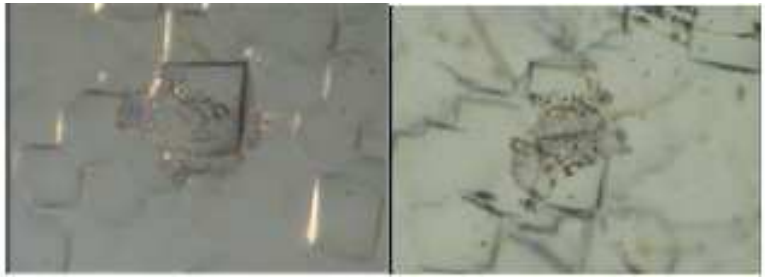

(a) $40 \mathrm{gF}$

(b) $60 \mathrm{gF}$

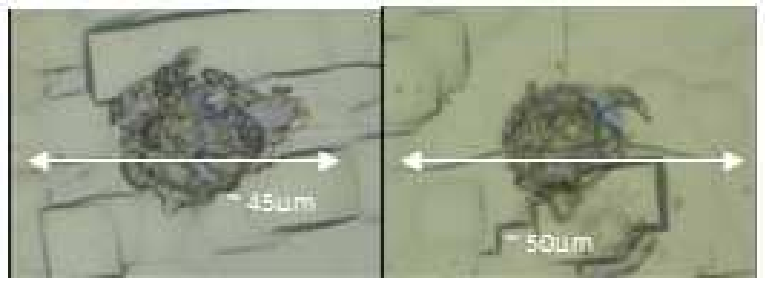

(C) $80 \mathrm{gF}$

(d) $100 \mathrm{gF}$

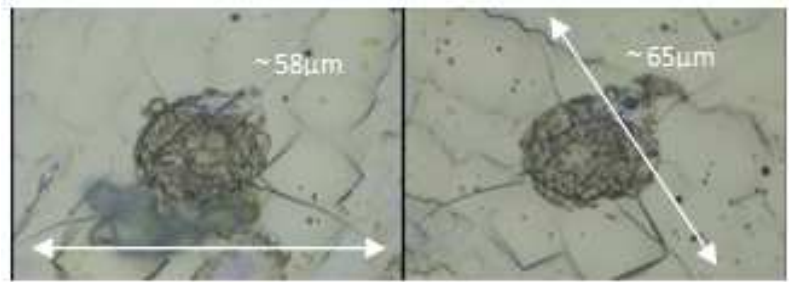

(e) $120 \mathrm{gF}$

(f) $140 \mathrm{gF}$

Figure 7. Showing ejector pin indentation photo from High Magnification scope.

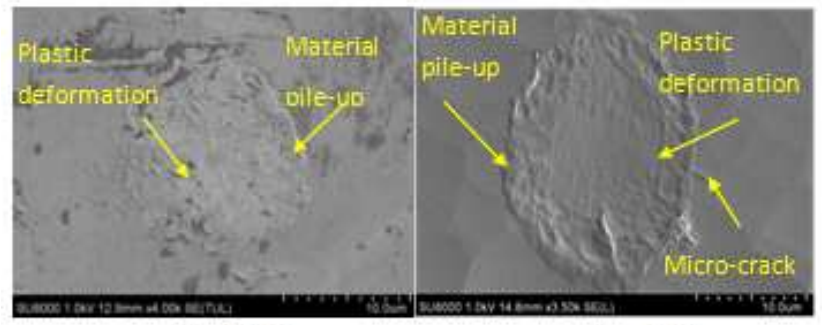

(a) $40 \mathrm{gF}$

(b) $60 \mathrm{gF}$

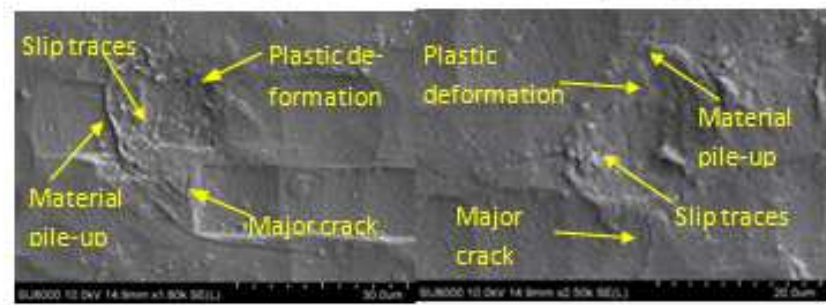

(c) $80 \mathrm{gF}$

(d) $100 \mathrm{gF}$

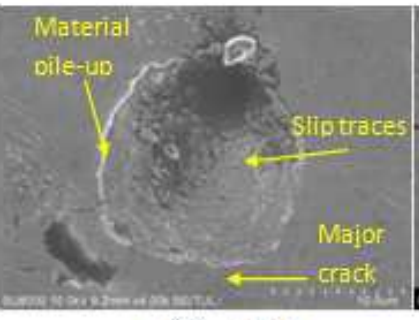

(e) $120 \mathrm{gF}$

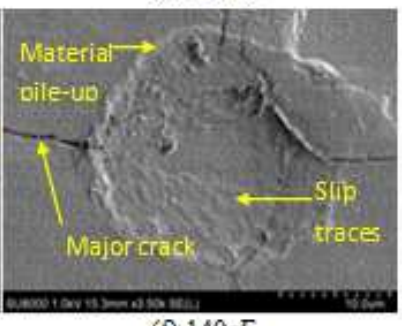

(f) $140 \mathrm{gF}$
Figure 8. Showing ejector pin indentation photo from SEM Analysis.
SEM micrographs of indented substrate surface for various bond force are shown in figure 8(a-f). The figure depicts that at $40 \mathrm{gF}$ no crack occurs. However at $60 \mathrm{gF}$ a small crack $(\sim 5 \mu \mathrm{m})$ can be observed in some of the dies. Note that these SEM images have been displayed after removing the metallization layer using IM from the surface of the die. At $80 \mathrm{gF}$, the crack length increases up to $45 \mu \mathrm{m}$. At $100 \mathrm{gF}, 120 \mathrm{gF}$, and $140 \mathrm{gF}$ bond force, the crack length is roughly $50 \mu \mathrm{m}$, $58 \mu \mathrm{m}$, and $65 \mu \mathrm{m}$ respectively.

A comparison has been drawn between the depth of cracks observed at $60 \mathrm{gF}$ and $140 \mathrm{gF}$ respectively. For this purpose the FIB cross-sectional analysis is shown in figure 9. At $60 \mathrm{gF}$ the crack is not as deep as compare to $140 \mathrm{gF}$. This is attributed to higher bond force which produces a large amount of plastic deformation, resulting in the production of a deep crack.

Figure 9-a and $b$ illustrate the cross section of the crack die using FIB cut. The finding shows that at $60 \mathrm{gF}$, the crack depth beneath the Ge surface is about $16.2 \mu \mathrm{m}$. However, at $140 \mathrm{gF}$ the crack looks much more severe with depth of $20.5 \mu \mathrm{m}$.

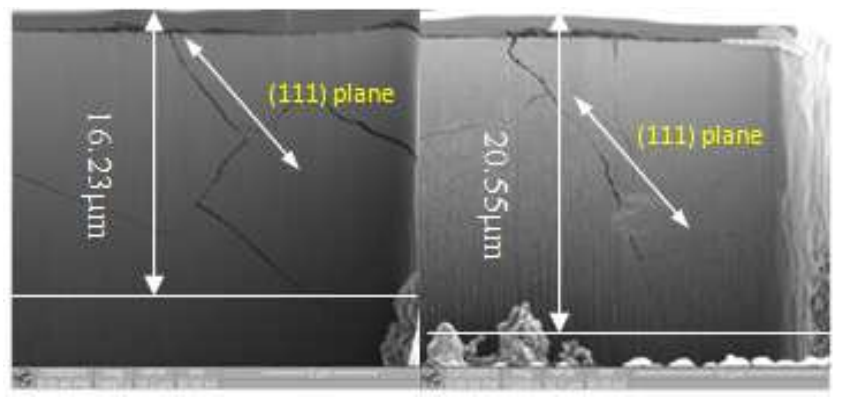

$\begin{array}{ll}\text { (a) } 60 \mathrm{gF} & \text { (b) } 140 \mathrm{gF}\end{array}$

Figure 9. Showing FIB cross-section view of cracked Ge substrate.

\subsection{Discussion}

The formation of crack is due to large amount of dislocations generation in the specimen as result of the bond force. Crack die degrades the LED electro-optical properties and can cause serious electrical failure [7, 21, 22]. Therefore these cracks must be avoided to ensure the LED performance are not affected [23, 24].

The results show that the Ge substrate of AlInGaP dies undergoes surface deformation at $40 \mathrm{gF}$ bond force and above. This finding is quite similar to the findings of Bradby et.al [14] and Oliver et.al [25], where plastic deformation on Ge was found under certain indentation load at room temperature.

In this experiment at $60 \mathrm{gF}$ bond force, micro-cracks were observed in some of the $2^{\text {nd }}$ batch dies. Major crack started to appear when bond force reached at $80 \mathrm{gF}$ onwards. This indicates that interatomic forces overcome the indentation forces induced by the ejector pin. Separation occurs when stress applied to the Ge substrate is sufficient to exceed the maximum force per bond. Hence fracture is bound to occur.

Stress at which this bond break takes place is also called

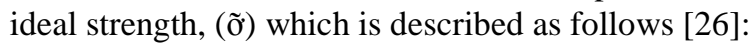

$$
\tilde{\sigma} \approx E / 15
$$

Here $\mathrm{E}$ is the Modulus Elasticity and it's value for Ge is at 
$103 \mathrm{GPa}$ [6]. The ideal strength of Ge will be roughly $6.87 \mathrm{GPa}$ Where else stress applied to the Ge Substrate through the ejector pin at $60 \mathrm{gF}$ bond force is $7.49 \mathrm{GPa}$ is calculated using equation 3 :

$$
\sigma=F / \pi a^{2}
$$

When $\mathrm{a}=5 \mu \mathrm{m}$, the stress induced by ejector pin is slightly greater than the ideal strength of $\mathrm{Ge}$, which causes the crack. In this investigation it is also demonstrated that there was no crack at $40 \mathrm{gF}$ because the stress induced at this force is just $5 \mathrm{GPa}$ which is far lower than the ideal strength of Ge. On the other hand, at $60 \mathrm{gF}$ only some micro-cracks observed in one of the wafer batch can be explained as follows. This could be due to slight variation of metallization layer on the die substrate. The metallization layer on the substrates is mainly for protecting the substrate from the oxidation or corrosion [27].

This crack phenomenon can be explained on the basis of Griffith energy balance criterion [16]. In this concept, all of the potential energy released was used in the creation of the new free surface on the crack faces [28]. The rate of changes of potential energy with increase in the crack area is defined as the strain energy release rate, $G$.

$$
\mathrm{G}=-1 / \mathrm{t} \cdot \mathrm{dU} / \mathrm{da}
$$

$G$ is the strain energy, $U$ is potential energy stored in Ge.

Here, the change in crack area is $t . d a$, and negative sign causes $G$ to have a positive value. Thus, $G$ characterizes the energy per unit crack area required to extend the crack.

The force exerted is proportional to stress which determined the material deformation and crack formation [28, 29]. The potential energy $U$ stored in the Ge substrate, as a result of the elastic strains throughout its volume is, equal to force F, times the displacement at the point of loading, $v$, as given below [28]:

$$
\mathrm{U}=\mathrm{F} . \mathrm{v} / 2
$$

As shown in Figure 6, when the force was increased gradually from $80 \mathrm{gF}$ to $140 \mathrm{gF}$, the crack length increases relatively to the bond force applied on the Ge substrate. As the force increases, the energy exerted to the Ge atomic bond also increases proportionally and more bonds were broken which results in increase of crack length.

As the bond force increases, the slip traces get more visible in the indented area. Crack shown in figure $9 \mathrm{a} \& \mathrm{~b}$ are along the (111) crystal planes of Ge [29, 30]. This is in agreement with the findings of Bradby et.al in which the indented Ge at $50 \mathrm{mN}$ showed defects along the (111) planes [14]. Zone in the immediate vicinity of the imprint is strongly strained. At $60 \mathrm{gF}$ bond force, only some material deformation is observed. However, at $140 \mathrm{gF}$ the material deformation is found to be worse. As expected, with increase of the bond force, the indentation depth also increases relatively. The depth of the crack at bond force $60 \mathrm{gF}$ is only at $16.23 \mu \mathrm{m}$ and for $140 \mathrm{gF}$ is at $20.55 \mu \mathrm{m}$. It is almost $170 \mu \mathrm{m}$ away from the epitaxial layer. This poses no threat to the epitaxial layer. However, such cracks seen in figure 7 and 8 may further propagate and may cause the LED to fail, when the LED is subjected to thermo-mechanical stresses [24]. This is always a concern and has to be addressed.

Hence, to further investigate, it is recommended to subject these crack die LEDs in using thermal stress test for example Power Temperature Cycle test or Temperature Cycle test in accordance to JEDEC standard.

\section{Conclusion}

This research provides important information to LED manufacturers who are using Ge substrate in their LED. The finding of this investigation has demonstrated that the minimum or safe bond force for this AlInGaP die on germanium substrate, using ejector pin radius of $25 \mu \mathrm{m}$ is lower than $60 \mathrm{gF}$. Beyond this bond force, cracks will occur on the Ge substrate. This investigation also shows that even though the crack length is increasing relative to bond force, the crack depth also increases but relatively small and is confined to the surface level that is far away from the active region of the LED die. The crack formation observed in this Ge substrate is along the (111) planes. This is in agreement with other researcher findings as well as the natural crystal structure order of Ge.

\section{Acknowledgements}

The authors would like to express their sincere gratitude to Dr. David Lacey, Dr. Shanmugam and R\&D Lab staff of OSRAM Opto Semiconductor (M) Sdn. Bhd.

\section{References}

[1] Matteo Meneghini, Augusto Tazzoli, Giovanna Mura, Gaudenzio Meneghesso, and Enrico Zanoni, “ A Review on the Physical Mechanisms that Limit the Reliability of GaN-Based LEDs", IEEE, 2009, pp108 - 110.

[2] Jasprit Singh "LED Reliability Issue", in Semiconductor Optoelectronics Physics and Technology, $1^{\text {st }}$ ed., New York, US: McGraw-Hill International Editions, 1995, pp 475-477.

[3] Chen Zhaohui, Zhang Qin, Wang Kai, Luo Xiaobing and Liu Sheng, "Reliability Test and Failure Analysis of High Power LED Packages", Journal of Semiconductors, Vol.32, No.1, 2011, pp. 1.

[4] Jiejie Fan, K.C.Yang and Michael Pecht, "Physics-of-Failure-Based Prognostics and Health Management for High-Power White Light-Emitting Diode Lighting", IEEE Transactions on Devices and Material Reliability, Vol.11.No 3, 2011, pp1-2.

[5] Shan GaO, Jupyo Hong, Sanghyun Shin, Yongki Lee, Seogmoon Choi, Sung Yi, "Design Optimization on the Heat Transfer and Mechanical Reliability of High Brightness Light Emitting Diodes (HBLED) Package", IEEE, 2008, pp798.

[6] Janzheng $\mathrm{Hu}$, Lianqiao Yang, Woong Joon Hwang, Moo Whan Shin, " Thermal and mechanical analysis of delamination in GaN-Based LED Packages", Journal of Crystal Growth, Elsevier, 2006, pp157-158. 
[7] Ugo Lafont, Henk van Zeijl, Sybrand van der Zwaag, "Increasing the reliability of solid state lighting system via self-healing approaches: A review", Journal of Microelectronics Reliability, vol. 52, 2012, pp 71-89.

[8] S. Abdullah, M.F. Abdullah, A.K. Ariffin, Z.A. Aziz and M.J. Ghazali, " Thermal-Mechanical Analysis of a QFN Stacked-Die Leadframe Under Reflow Process”, WCE, 2008, pp 1-2.

[9] Shin-Yueh, Tsung-Lin Chou, Chen-Fu Huang, Chung-Jung Wu, Chia-Liang Hsu, and Kuo-Ning Chiang, "Determination of Maximum Strength and Optimization of LED Chip Structure", E-mail : knchiang@pme.nthu.edu.tw

[10] C. Chen, M. Tsai, J. Tang, W. Tsai and T. Chen, "Determination of LED Die Strength," in International conference of EMAP, Daejeon, 2008, pp. 1-6.

[11] Japan Creation Manufacturer - Full Automated Die Bonder Operation Manual, Serial No. 175. Version 1. 2010, pp. 1-5.

[12] T. Taishi, Yonenaga and K. Hoshikawa, "Improved Czochralski Growth of Germanium Single Crystals from a Melt Covered By Boron Oxide", Acta Physica Polonica A, Vol. 124, 2013, pp 232.

[13] C. Claeys and E. Simoen, "Germanium Material" in Germanium-Based Technologies: From Materials to Devices, $1^{\text {st }}$ ed. Oxford, UK: Elsevier Limited, 2007, pp. 11.

[14] J.E. Bradby, J.S.Willams, J.Wong-Leung, M.V.Swain and P.Munroe "Nanoindentation-applied deformation of Ge", Applied Physics Letters, vol.80, 2002, pp. 2651-2653.

[15] Lawrence H. Van Vlack, "Atomic Bonding and Coordination" in Elements of Materials Science and Engineering, $6^{\text {th }}$ ed. Michigan, US: Addison-Willey, 1989, pp 48-52.

[16] A. A. Griffith. "The Phenomena of rapture and flow in solids". Philosophical Transactions of the Royal Society of London, Series A, 1921, pp. 163-198.

[17] A.C Fisher-Cripps, "The IBIS Handbook of Nanoindentation", Fisher-Cripps Laboratories Pty. Limited, NSW Australia, 2009.

[18] Micro Mechanics, "Ejector Pin Configuration", 2013, .http://www.micro-mechanics.com/product.php?id=102

[19] W.C Oliver, G.M. Pharr, "Measures of hardness and elastic modulus by instrumented indentation: Advances in understanding and refinements to methodology", Journal of Material Research, vol. 19, 2004, pp 6-12.
[20] "Correx Tension Gauge -Instruction for User" HAAG-STEIT International, Haag-Streit Companies, 2013.

[21] Shailesh KR, Ciji Pearl Kurian and Savitha G Kini, "Solid State Lighting Reliability from Failure Mechanisms Perspective: A Review of Related Literature", International Journal of Semiconductor Science \& Technology". Vol 3, No. 1, 2012, pp. 43-45, 46.

[22] Yuqi Jiang, Xianzhong Song, Tim Fai Lam, Surasez Samatitchen, "FBGA Die Crack Issue Analysis", IEEE, 1-4244-1253-6/07, 2007, pp 1-2.

[23] Seung-Jae Lee, Kang Ho Kim, Jin-Woo Ju, Tak Jeong, Cheul-Ro Lee, and Jong Hyeob Baek, "High-Brightness GaN-Based Light-Emitting Diodes on Si Using Wafer Bonding Technology”, The Japan Society of Applied Physics, 2011, pp1-3.

[24] Guoguang Lu, Shaohua Yang, Yun Huang, "Analysis on Failure Modes and Mechanisms of LED", IEEE, 978-1-4244-4905-7/09, 2009, pp1238.

[25] D.J. Oliver, J.E Bradby, S.Ruffell, J.S Williams and P. Munroe, "Nanoindentation-applied phase transformation in relaxed and un-relaxed ion-implanted germanium", Journal of Applied Physics, vol.106, 2009, pp 4-5.

[26] Michael F Ashy \& David R H Jones. "The Yield Strength, Tensile Strength, Harness and Ductility", in Engineering Materials 1 - An Introduction to their Properties and Applications, $1^{\text {st }}$ ed. Oxford, UK: Pergamon Press, 1989, pp 79, 86-88.

[27] Mitsuo Fukuda, "Reliability -Basics of Degradation and Reliability", in Optical Semiconductor Devices, $1^{\text {st }}$ ed. New York, US: John Wiley \& Sons, Inc., 1999, pp 341-344.

[28] Norman E. Dowling "Fracture of Cracked Members", in Mechanical Behaviour of Materials - Engineering Methods for Deformation, Fracture and Fatique, $3^{\text {rd }}$ ed., New Jersey, US: Pearson Prentice Hall, $3^{\text {rd }}$ Edition, 2007, pp 322-323.

[29] Ohring Milton. "Electrons in Atoms and Solids: Bonding", in Engineering Materials Science, vol. 1, London, UK: Academic Press, 1995, pp: 59.

[30] B. R. Lawn, "Hertzian Fracture in Single Crystals with the Diamond Structure", Department of Defense Advanced Researh Projects Agency Contract SD-86, Material Research Program, Industrial Distribution Ltd, 1967, pp14-15. 